\title{
A Contabilidade na Era Digital: prospecção tecnológica para uma análise de tendências
}

\author{
The Accounting in the Digital Age: technological \\ prospection for trend analysis
}

\author{
Edilson Ponciano de Lima ${ }^{1}$ \\ Erivaldo Oliveira de Matos ${ }^{1}$ \\ Vinícius José Ferro Gomes ${ }^{1}$ \\ João Paulo Lima Santos ${ }^{1}$ \\ Danielle Clara Santana da Silva ${ }^{1}$ \\ ${ }^{1}$ Universidade Federal de Alagoas, Maceió, AL, Brasil
}

\begin{abstract}
Resumo
Este trabalho prospectivo busca investigar de forma sistemática os desenvolvimentos tecnológicos de temas que são tendências no universo contábil e financeiro. As informações apresentadas através de busca patentária concentramse em demonstrar a evolução de depósitos de famílias de patentes por ano de publicação, as famílias de patentes por país de proteção, os principais players do mercado a partir da relação dos principais depositantes e as áreas de domínio das tecnologias pesquisadas. A pesquisa foi realizada através de cruzamentos dos temas tecnológicos relacionados à contabilidade pelos termos "accounting" e "accountancy", sendo realizada busca no sistema de inteligência Questel-Orbit ${ }^{\circledR}$. A pesquisa obteve os seguintes resultados por áreas pesquisadas: Data Analytics, Blockchain, Internet of things, auditoria/tributação e, por fim, o uso de inteligências artificiais. Os resultados foram comparados, analisados e debatidos sob a perspectiva de seus impactos sobre a área contábil.
\end{abstract}

Palavras-chaves: Contabilidade. Inteligência Artificial. Fintechs.

\begin{abstract}
This prospective work seeks to systematically investigate the technological developments of topics that are trends in the accounting and financial universe. The information presented through patent search focuses on demonstrating the evolution of patent family filings by year of publication, patent families by country of protection, the main market players from the list of major filers and the areas of domain of the researched technologies. The research was carried out by crossing the technological themes related to accounting by the terms "accounting" and "accountancy" researched at the Questel-Orbit ${ }^{\circledR}$ intelligence system. The research obtained the following results by researched areas: Data Analytics, Blockchain, Internet of things, audit/taxation and, finally, the use of artificial intelligence. The results were compared, analyzed and debated from the perspective of their impacts on the accounting area.
\end{abstract}

Keywords: Accounting. Artificial Intelligence. Fintechs.

Área Tecnológica: Contabilidade. Tecnologia da Informação. Inteligências Artificiais. 


\section{Introdução}

\subsection{A Contabilidade na Era Digital}

Segundo Santos (2015), passadas quase duas décadas, empresas introduziram no mercado soluções e modelos de negócios inovadores que permitiram reduzir custos e competir com empresas e serviços há muito tempo estabelecidos. Novos mercados surgiram para suplantar as novas demandas da era digital. Sendo assim, as mudanças na produção de bens e serviços alteraram a rotina de diversas profissões dentro das organizações.

A tecnologia da informação tem sido uma grande aliada do profissional contábil, produzindo vários impactos na contabilidade e na atuação do profissional (CORDEIRO; DUARTE, 2006). Silva e Kruger (2012) afirmam que os profissionais contábeis necessitam estar atentos às mudanças, pois se vivencia a era do conhecimento e da informática dentro da própria contabilidade, o que exige muito do capital intelectual $e$ a procura de profissionais cada vez mais preparados para atender às necessidades do fisco e do mercado. O profissional contábil, no desenvolvimento de suas funções, aplica conhecimentos específicos da ciência, da tecnologia $e$ ainda apela para complementos oriundos de disciplinas correlatas, como a administração, economia, direito e sociologia (SILVA; KRUGER, 2012).

\subsection{Novos Modelos de Negócios Tecnológicos na Contabilidade}

Criadas e desenvolvidas nos Estados Unidos com o intuito de promoverem melhorias em ambientes de empreendedorismo, as startups são empresas recém-criadas ou em processo de desenvolvimento que se utilizam de pesquisas e desenvolvimento (P\&D) e tecnologia num mercado de extrema incerteza (ABSSTARTUPS, 2017).

Fintechs são, em geral, startups que criam inovações na área de serviços financeiros incorporando tecnologias que tornam o mercado de finanças e seus sistemas mais eficientes. Essas empresas de tecnologia em finanças, na maioria das vezes, são criadas com o propósito de romper com os paradigmas do sistema financeiro tradicional, que conta pouco ou de maneira ineficiente com os recursos tecnológicos disponíveis. O fenômeno das fintechs tem obrigado as instituições financeiras tradicionais a correrem contra o tempo, buscando por modernização de processos e fidelização dos clientes para que possam continuar estáveis no mercado atual (CONEXÃO FINTECH, 2017).

De acordo com Purchio (2017), um fator que também teve grande influência no mercado financeiro foi o aparecimento e uso cada vez mais constante de moedas virtuais. As moedas virtuais permitem transações financeiras instantâneas e, até agora, imunes a fraudes.

Ao invés de ver a história da Contabilidade como uma evolução natural das tecnologias administrativas, cada vez mais a Contabilidade é vista como a base conceitual e lógica de um determinado complexo de racionalidades financeiras e modos de intervenção na gestão empresarial, um complexo que foi formado a partir da integração de dados por meio de uma gama heterogênea de questões e eventos ligados ao âmbito financeiro dos negócios (CARNEGIE; NAPIER, 1996). 


\subsection{Conceitos das Tecnologias Aplicadas à Contabilidade}

Através de SILVA (2017), percebe-se que o avanço tecnológico abrange diversas áreas e situações. A evolução, com o passar do tempo, é notória, principalmente em relação ao surgimento de alternativas de meios de pagamento, análise de dados e softwares de gestão integrada, destacando-se as seguintes tecnologias.

\subsection{Data Analytics}

Ao tratarmos de análise de dados, também estamos tratando de "big data". Segundo Taurion (2013), "big data" não trata somente de volume de dados, mas da necessidade desses dados não estruturados serem validados nas empresas e fora delas para que possam ser utilizados com segurança e contar com a velocidade adequada, para que possam ser tratados em tempo real, sem perderem valor quando utilizados nos negócios.

Segundo Hieaux (2015), a Internet das Coisas aliada ao uso de big data dará base para uma economia de produtos e serviços personalizados, pois os consumidores terão o perfil mapeado, com seus dados coletados e analisados, com isso empresas ofertarão serviços cada vez mais customizados aos desejos e necessidades de seus clientes. De acordo com dados da Internacional Data Corporation (2016), empresa que presta serviços de consultoria nas indústrias de TI, telecomunicações e mercados de consumo em massa de tecnologia em pesquisa comparativa feita na América Latina, a projeção de mercado da IoT em 2014 foi de USD 7 bilhões, e para 2020 a estimativa é de USD 15,6 bilhões.

\subsection{Blockchain}

De acordo Salah, K. et al. (2019) o blockchain pode ser altamente efetivo em termos de custo para eliminar a necessidade de uma autoridade centralizada para governar e verificar interações e transações entre todos os participantes. A tecnologia foi construída tendo em mente quatro principais características arquiteturais: segurança das operações, descentralização de armazenamento/computação, integridade de dados e imutabilidade de transações.

Associado ao uso do Bitcoin, o "blockchain", segundo a Fundação CDqP - Centro de Pesquisa e Desenvolvimento em Telecomunicações (2017, p. 06), pode ser entendido de diversas maneiras, onde o conceito mais sucinto seria o de que "se trata de um sistema distribuído de base de dados em log, mantido e gerido de forma compartilhada e descentralizada (através de uma rede peer-to-peer, P2P), na qual todos os participantes são responsáveis por armazenar e manter a base de dados".

\subsection{Internet of things}

Segundo o conceito apresentado por Oliveira et al. (2016), a IoT (Internet of Things) surgiu para explicar a convergência de múltiplas tecnologias que envolvem a comunicação sem fio, internet, sistemas embarcados e microeletromecânicos. Cada objeto é identificado através do seu sistema de software embarcado e é capaz de interoperar com a infraestrutura de internet existente. Os principais componentes de uma rede IoT podem ser, por exemplo, aparelhos ce- 
lulares e eletroeletrônicos, sensores, computadores, aparelhos de televisores, ar condicionados, lâmpadas e diversos outros dispositivos utilizados tanto no ambiente doméstico quando na aplicação industrial.

\subsection{Auditoria e Tributação}

Segundo Santos et al. (2007), a auditoria fiscal compreende a revisão dos procedimentos fiscais que são adotados por uma determinada empresa, mediante o exame de documentos, livros e registros, declarações, inspeções e confirmações internas e externas, relacionados com o controle do patrimônio, objetivando mensurar os valores dos tributos e o registro das demonstrações contábeis. Segundo Carlin (2008), a importância de se discutir a realização de investimentos de tecnologias em auditoria e fiscalização tributária se justifica na medida em que o aprimoramento do Estado nessa área contribuirá, decisivamente, para a diminuição de um grande problema que assola o Brasil e que se chama sonegação fiscal.

\subsection{Inteligência Artificial}

Segundo Duarte (2018), as próximas décadas serão marcadas por inteligências artificiais atuando na contabilidade para mudar exponencialmente a forma como reunimos informações, tomamos decisões e nos conectamos com as partes interessadas. Isso porque a definição de inteligência artificial está relacionada à capacidade das máquinas de pensarem como seres humanos - de terem o poder de aprender, raciocinar, perceber, deliberar e decidir de forma racional e inteligente. Os benefícios das inteligências artificiais na Contabilidade podem servir de apoio em decisões mais complexas em áreas como recursos humanos, orçamento, marketing $e$ até estratégias corporativas.

\section{Metodologia}

De acordo com Kupfer e Tigre (2004), uma "prospecção tecnológica" pode ser definida como uma forma sistemática de mapear desenvolvimentos científicos e tecnológicos futuros capazes de influenciar de forma significativa uma indústria, a economia ou a sociedade.

Para acessar, filtrar e analisar as informações contidas nos documentos de patentes foi utilizado o sistema de inteligência Questel-Orbit ${ }^{\circ}$, ferramenta de busca de patentes com atualizações diárias, tendo disponível mais de 54 milhões de famílias de patentes e mais de 100 milhões de patentes com cobertura mundial.

A pesquisa foi realizada por cruzamentos de palavras-chaves de temas tecnológicos e os termos representativos da contabilidade em língua inglesa, "accounting" e "accountancy", conforme detalhado no Quadro 1. Realizou-se uma análise patentária entre os dias 1\%/06/2019 e 02/06/2019. As pesquisas foram realizadas utilizando-se strings de busca compostos por operadores boleanos, sem restrições temporais, utilizando-se os campos de busca referentes a título, resumo e conceito das patentes. 
Quadro 1 - Strings de busca utilizados na pesquisa

\begin{tabular}{|c|c|}
\hline IDENTIFICADOR & Descrição \\
\hline 01 & (accounting OR accountancy) AND (data analytics) \\
\hline 02 & $\begin{array}{c}\text { (accounting OR accountancy) AND (blockchain OR } \\
\text { (decentralized technology) OR (distributed ledger)) }\end{array}$ \\
\hline 03 & (accounting OR accountancy) AND (audit OR auditorship OR auditing) AND (tax OR tribute) \\
\hline 04 & (accounting OR accountancy) AND (algorithm OR robot OR (artificial intelligence)) \\
\hline 05 & (accounting OR accountancy) AND ((internet of things) OR iot)) \\
\hline
\end{tabular}

Fonte: Elaborado pelos autores deste artigo (2019)

\section{Resultados e Discussão}

As famílias de patentes resgatadas pelo mecanismo de busca Questel-Orbit $\AA$ apresentaram os seguintes resultados por áreas tecnológicas pesquisadas (Figura 1): Data Analytics um total de 172 famílias de patentes, Blockchain um total de 530 famílias de patentes, Internet of things 995 famílias de patentes, Auditoria e Tributação 1.668 famílias de patentes e, por fim, inteligência artificial com 12. 217 famílias de patentes.

Ao se observar a disposição dos números de depósitos de famílias de patentes é possível notar a desproporcionalidade entres as inovações tecnológicas, com destaque para a inteligência artificial, que possui um montante de patentes muito superior às outras tecnologias.

Analisando o intervalo temporal entre os anos de 1999 a 2018 (Figura 1), é possível perceber depósitos de famílias de patentes ao longo de todo o recorte temporal das tecnologias referentes à auditoria e tributação, inteligência artificial e internet of things.

No caso das invenções envolvendo data analytics é possível perceber um aumento significativo no número de depósitos de famílias de patentes a partir do ano de 2013, com o número de 12 depósitos, e ápice no ano de 2016 com 32 depósitos. De acordo com Kambatla et al. (2014), o cenário emergente de ambientes baseados em nuvem com datacenters distribuídos que hospedam grandes repositórios, a diversidade de características de aplicativos e os benefícios socioeconômicos subjacentes da data analytics apresentam-se como desafios significativos para a construção de novos inventos dessa tecnologia.

As invenções referentes à tecnologia blokchain surgem apenas a partir do ano de 2009, uma vez que a tecnologia é exposta no ano de 2008 através do white paper de seu inventor, Satoshi Nakamoto. É possível evidenciar uma elevação significativa no número de depósitos de famílias de patentes a partir do ano de 2015, com o número de 13 depósitos, e ápice no ano de 2018 com 240 depósitos (Figura 1). 
Figura 1 - Linhas de evolução temporal de depósito de família de patentes das tecnologias

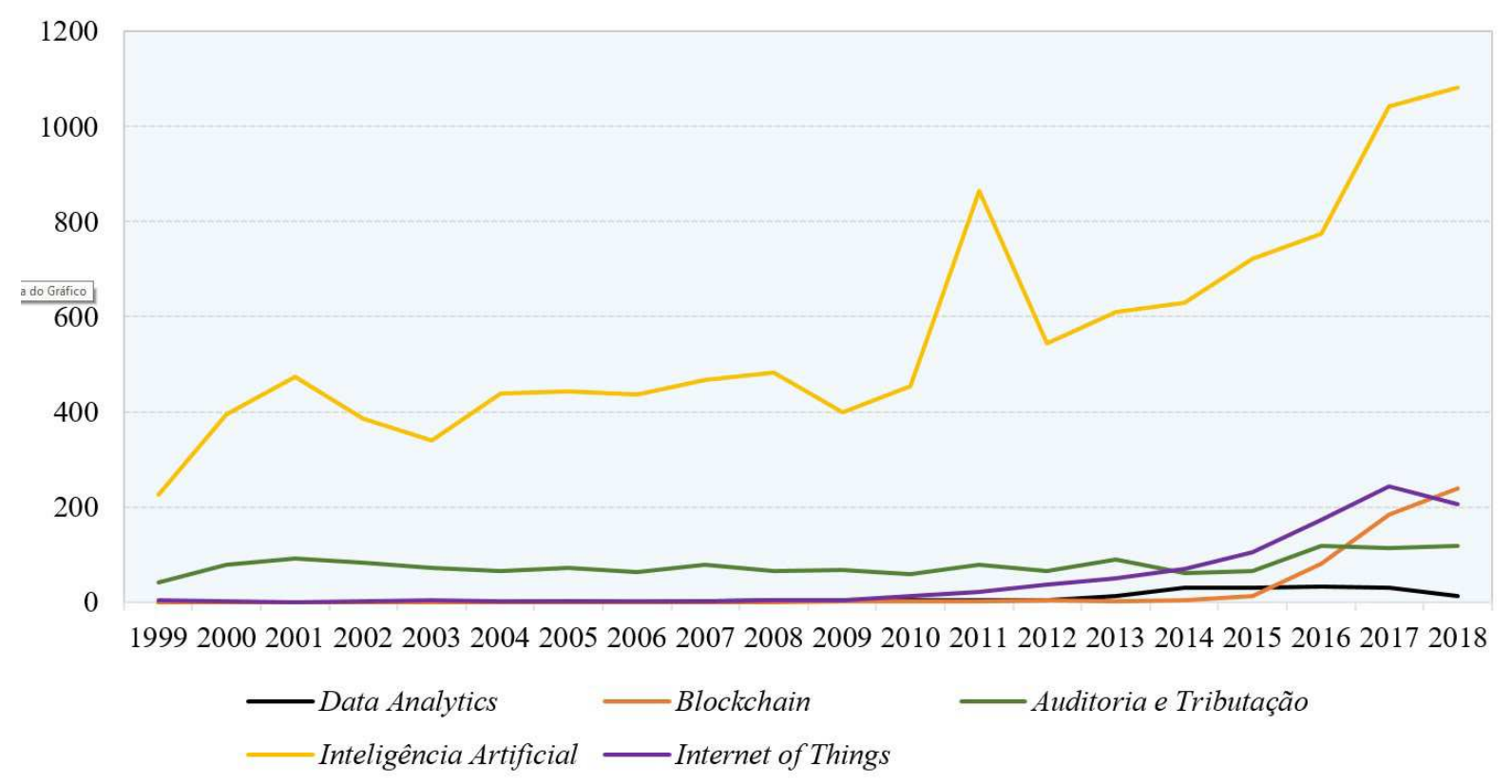

Fonte: Elaborada pelos autores deste artigo (2019)

\subsection{Data Analytics}

De acordo com os resultados resgatados das famílias de patentes relacionadas à contabilidade e data analytics foi possível elencar as principais empresas depositantes. Liderando o número de depósitos de famílias de patentes de data analytics está a empresa Amdocs Development, fornecedora de software e serviços para empresas de comunicação e mídia de todos os portes, com o total de 33 famílias de patentes depositadas. Também é possível perceber grandes players do mercado de tecnologia da informação no rol das principais depositantes, como a chinesa Huawei, a americana IBM, e a alemã SAP, conforme Figura 2.

Figura 2 - Principais depositantes de famílias de patentes relacionadas a contabilidade e data analytics Key players

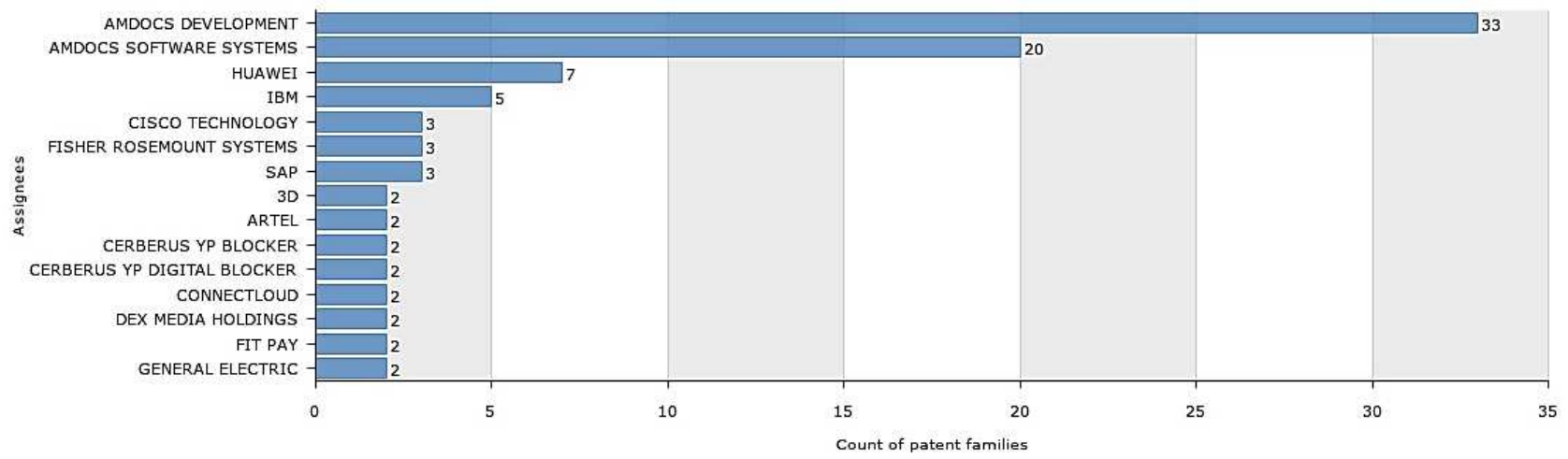

Fonte: Questel-Orbit ${ }^{\circledR}(2019)$

Os principais países de proteção das patentes desenvolvidas com a tecnologia data analytics (Figura 3) são os Estados Unidos da América com 134 famílias de patentes, o escritório euro- 
peu de patentes com 44 famílias de patentes e China com 35 famílias de patentes. Esse estudo permite monitorar os principais mercados de proteção, além de permitir a elaboração de novas estratégias de proteção de tecnologia. A Figura 3 apresenta um mapa indicando os principais mercados de proteção das tecnologias relacionadas a contabilidade e data analytics.

Figura 3 - Principais países de proteção relacionadas à contabilidade e data analytics

\section{Markets \& competitors location}

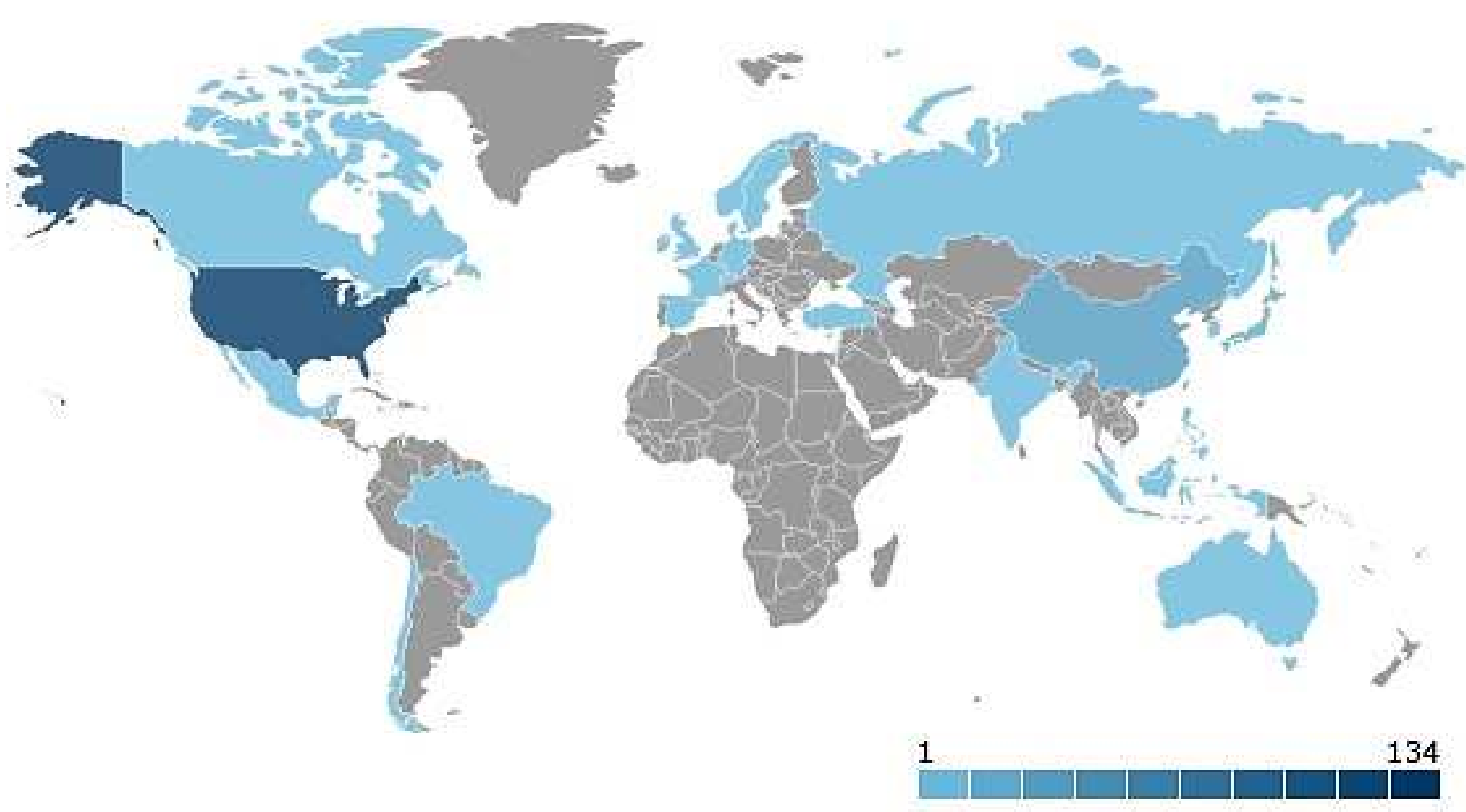

(9) Questel 2019

Fonte: Questel-Orbit巴 (2019)

As principais tecnologias dominantes das 172 famílias de patentes resgatadas para a contabilidade e data analytics são Computer Technology com 28,47\%, Digital Communication com 27,08\% e It Methods for Management com 20,14\% do total das famílias de patentes.

\subsection{Blockchain}

Ao analisar as famílias de patentes resgatadas relacionadas à contabilidade e blockchain (Figura 4) foi possível identificar grandes players do mercado financeiro, empresas de tecnologia e varejistas de grande porte mundial. Liderando as empresas depositantes está a Mastercard International com 11 famílias de patentes depositadas, em seguida a varejista chinesa Alibaba Holding com 10 famílias de patentes depositadas. A Figura 4 detalha o rol das 15 principais depositantes de famílias de patentes relacionadas à contabilidade e blockchain. 
Figura 4 - Principais depositantes de famílias de patentes relacionadas à contabilidade e blockchain

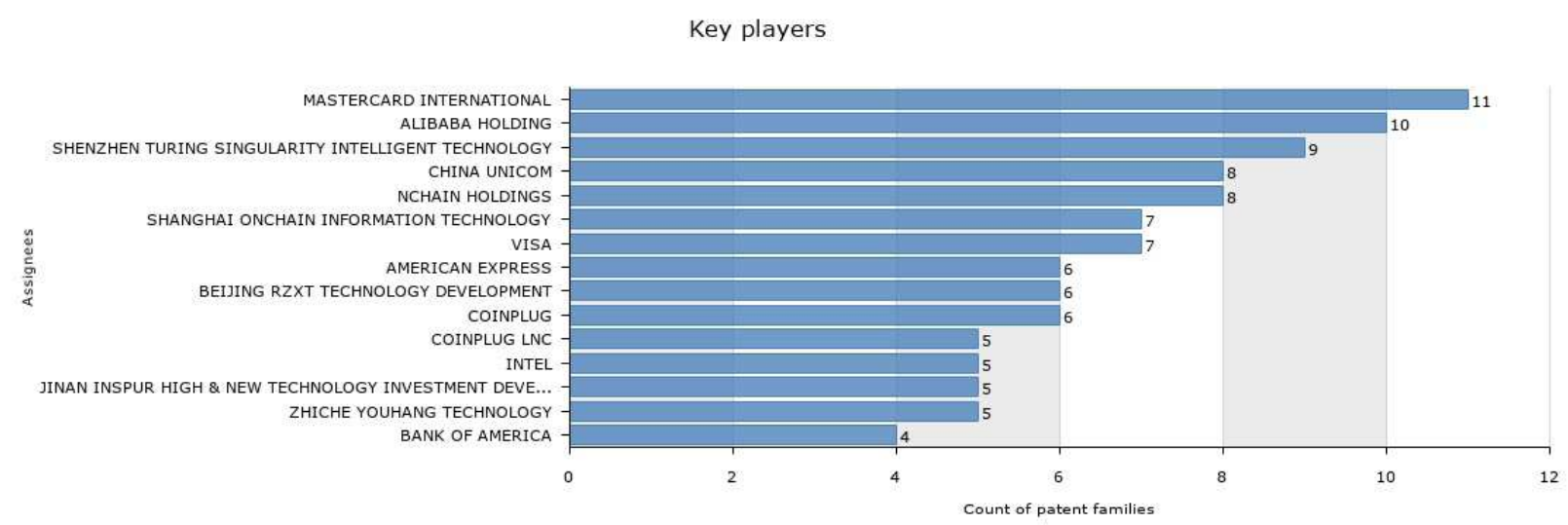

(c) Questel 2019

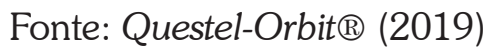

Os principais países de proteção das patentes desenvolvidas com a tecnologia blockchain são a China com 312 famílias de patentes e os Estados Unidos da América com 181 famílias de patentes. É possível perceber um alto número de depósitos de famílias de patentes através da prática de PCT - Patent Cooperation Treaty, que auxilia os candidatos na busca de potencial proteção internacional de patentes para seus inventos e demonstra que a tecnologia blockchain tem uma forte abrangência global.

Das invenções relacionadas à contabilidade e blockchain, 530 famílias de patentes, apresentam predominância de tecnologias referentes a It Methods for Management com 47,78\%, Digital Communication com 30,25\%, Computer Technology com 10,25\%, e Control com 6,30\% do total das famílias de patentes.

\subsection{Internet of Things}

Os resultados referentes às empresas depositantes de família de patentes relacionadas à contabilidade e Iot apresentam como líder de depósitos a empresa Convida Wireless, empresa focada em pesquisas sobre o futuro da conectividade e da Internet das Coisas, com 30 famílias de patentes depositadas, seguida da State Grid Corporation of China (SGCC), empresa de energia na República Popular da China, que é responsável pela maior parte da operação da rede elétrica nacional, com 17 famílias de patentes depositadas; e na terceira posição está a empresa sul-coreana Samsung Electronics, reconhecida mundialmente como líder do setor de tecnologia, com 16 famílias de patentes depositadas.

Os principais países de proteção das tecnologias voltadas para Internet of things (Figura 5) são China com 576 famílias de patentes, mais que o dobro do quantitativo dos Estados Unidos da América, que fica em segunda posição com 206 famílias de patentes, e em seguida destaca-se o Escritório Europeu com 187 famílias de patentes. Fica perceptível através desse estudo o grande investimento feio pela República Popular da China para obter a liderança em Internet of things através da produção massiva de propriedade intelectual de dispositivos eletrônicos com conexão em rede para fins comerciais e governamentais. De acordo com Purdy e Davarzani (2015), a média de crescimento do PIB de países em desenvolvimento pode ir de 0,2\% a 0,5\% com investimentos em IoT. A República Popular da China será o maior beneficiada com a 
possibilidade de incremento de US\$1,8 trilhão com internet das coisas na indústria. A Figura 5 apresenta um mapa indicando os principais mercados de proteção das tecnologias relacionadas à contabilidade e Internet of things.

Figura 5 - Principais países de proteção relacionada à Contabilidade e à Internet of things

\section{Markets \& competitors location}

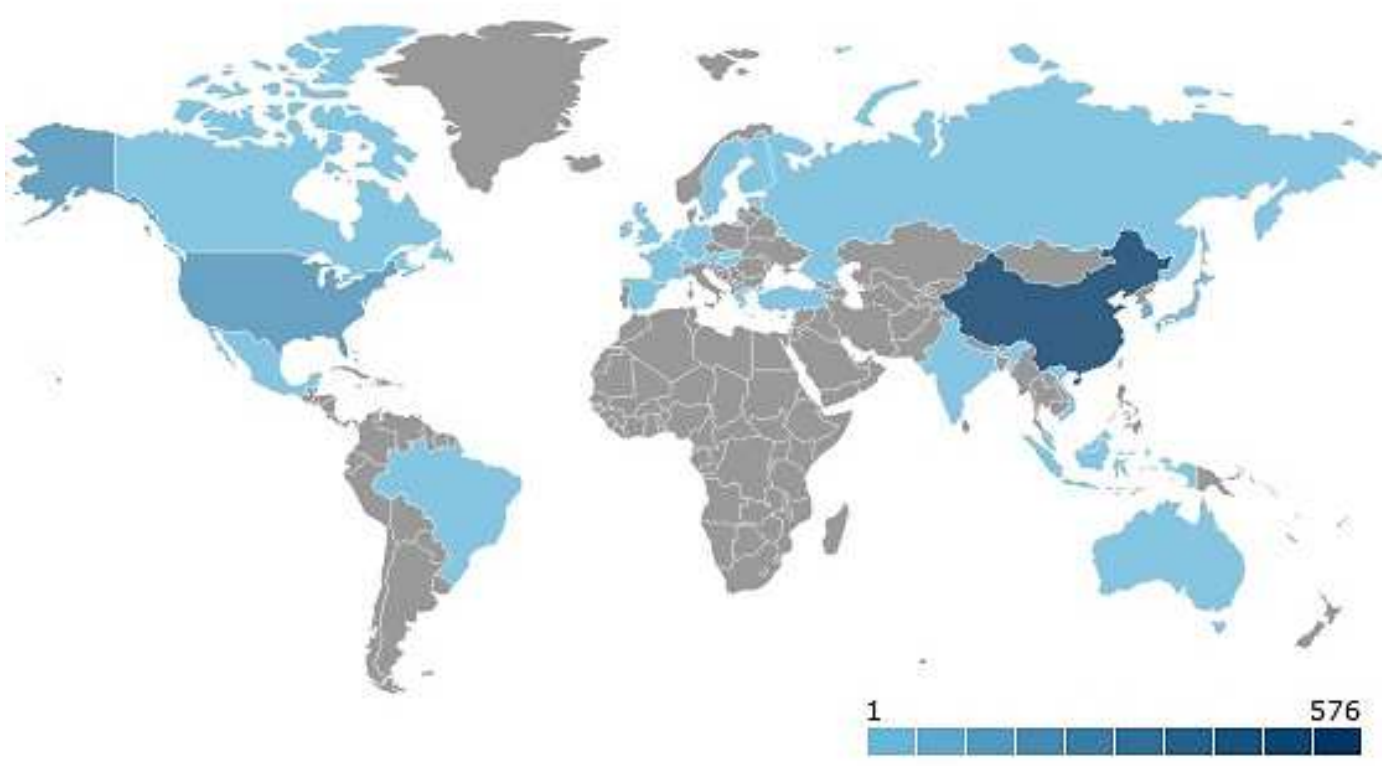

Fonte: Questel-Orbit ${ }^{(2019)}$

As invenções relacionadas à contabilidade e à Internet of things possuem uma vasta abrangência de tecnologias: as 995 famílias de patentes apresentam predominância de tecnologias referentes a Digital Communication com 25,12\%, It Methods for Management com 22,86\%, Control com 15,92\%, Telecommunications com 14,14\%, Computer Technology com 8,51\%, Measurement com 3,23\% e Electrical Machinery, apparatus, Energy com 2,61\% total das famílias de patentes, conforme a Figura 6.

Figura 6 - Domínio de tecnologia relacionado a contabilidade e Internet of things

Technology overview

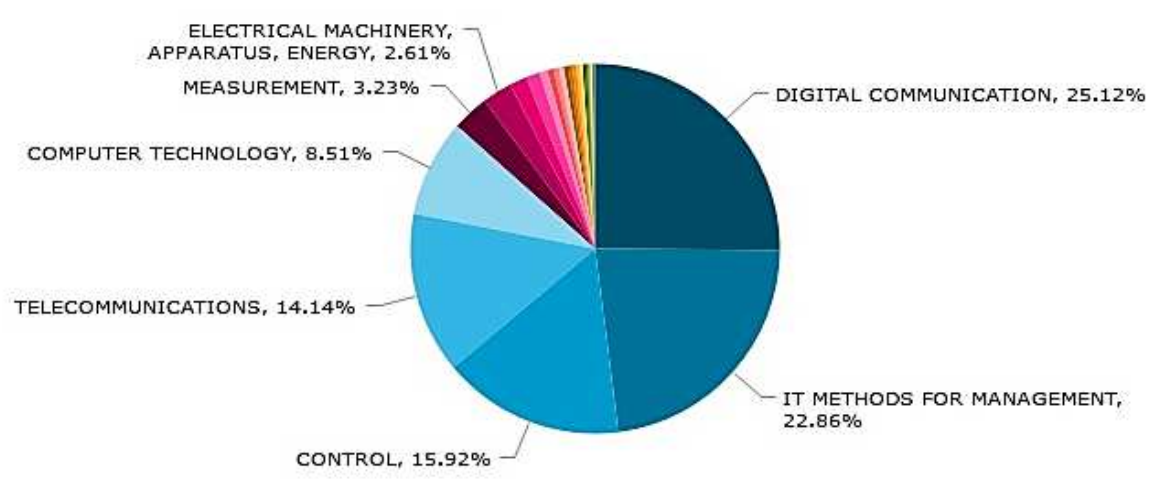

Fonte: Questel-Orbit@ (2019) 


\subsection{Auditoria e Tributação}

Os resultados referentes às empresas depositantes de família de patentes relacionadas à contabilidade e auditoria e tributação apresentam como principal depositante de patentes a empresa alemã SAP, líder no ramo de softwares empresariais no país, com 28 famílias de patentes depositadas; em seguida a empresa americana IBM com 22 famílias de patentes depositadas; e na terceira posição a empresa Aisino, empresa chinesa especializada em segurança da informação, que atua em um leque amplo de áreas de serviços, incluindo finanças, educação, alfândega, segurança pública e serviços urbanos, a qual possui 19 famílias de patentes depositadas.

Analisando o rol das principais empresas depositantes é possível perceber a presença de grandes corporações da tecnologia da informação como, por exemplo, a Oracle International, a empresa canadense Thomson Reuters, que trabalha respaldando profissionais dos setores financeiro e de risco; jurídico; fiscal, contábil e de gestão do comércio exterior; e de mídia. Também é possível detectar empresas destaques no mercado financeiro, como é o caso da JPMorgam Chase Bank e da Visa.

Os principais países de proteção das tecnologias voltadas para auditoria e tributação (Figura 7) são Estados Unidos da América com 434 famílias de patentes, seguidos da China com 378 famílias de patentes, e do Japão, na terceira posição com 114 famílias de patentes. Destaque também para Canadá e Austrália: ambos os países apresentam 77 famílias de patentes depositadas. O Brasil registrou apenas 20 famílias de patentes para esse tipo de tecnologia, o que aponta que o mercado brasileiro ainda não é atrativo para as grandes corporações. A figura 7 apresenta um mapa indicando os principais mercados de proteção das tecnologias relacionadas à contabilidade e auditoria e tributação.

Figura 7 - Principais países de proteção relacionada à contabilidade e auditoria e tributação

\section{Markets \& competitors location}
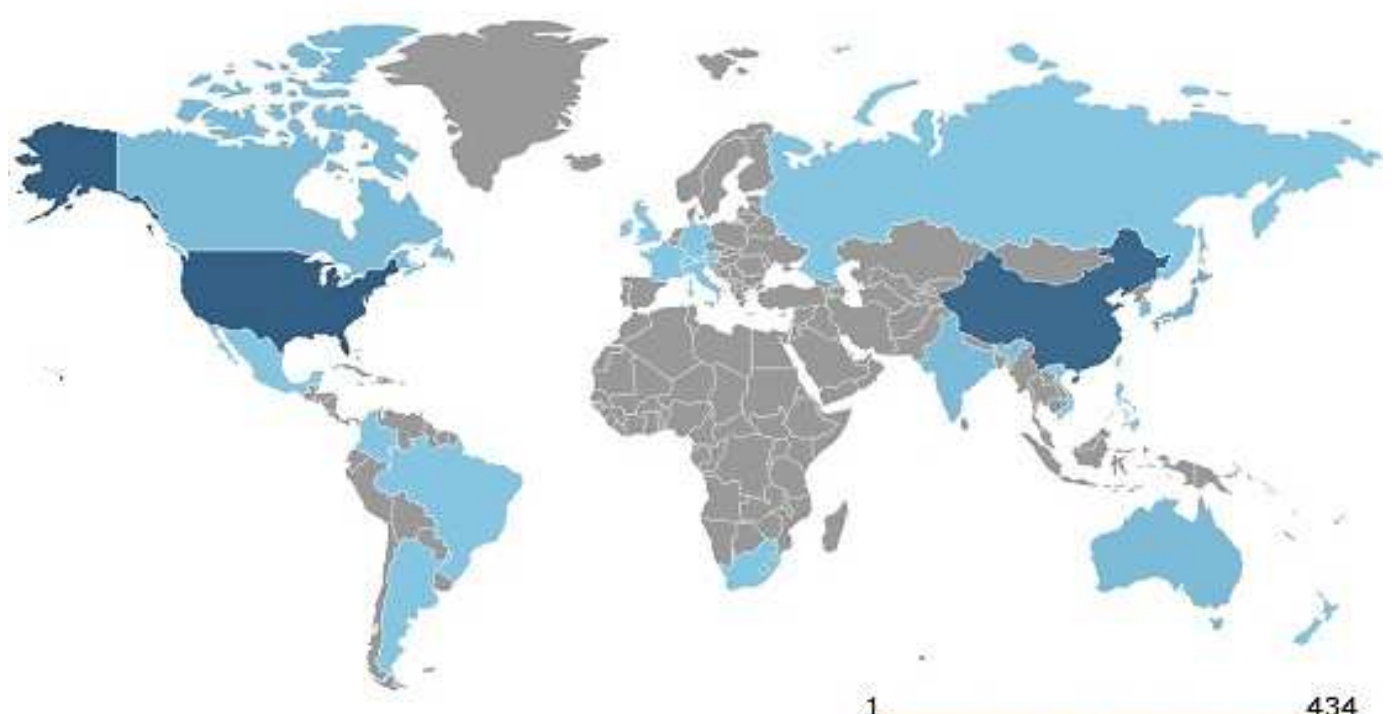

1 
As invenções relacionadas à auditoria e tributação possuem uma vasta abrangência de tecnologias. As 1.688 famílias de patentes apresentam predominância de tecnologias referentes a It Methods for Management com 55,9\%, Computer Technology com 12,3\%, Control com 11,7\%, Digital Communication com 8,0\%, Telecommunications com 3,1\% e Furniture, Games com 2,0\% do total das famílias de patentes, conforme a Figura 8.

Figura 8 - Domínio de tecnologia relacionado à Contabilidade e auditoria e tributação

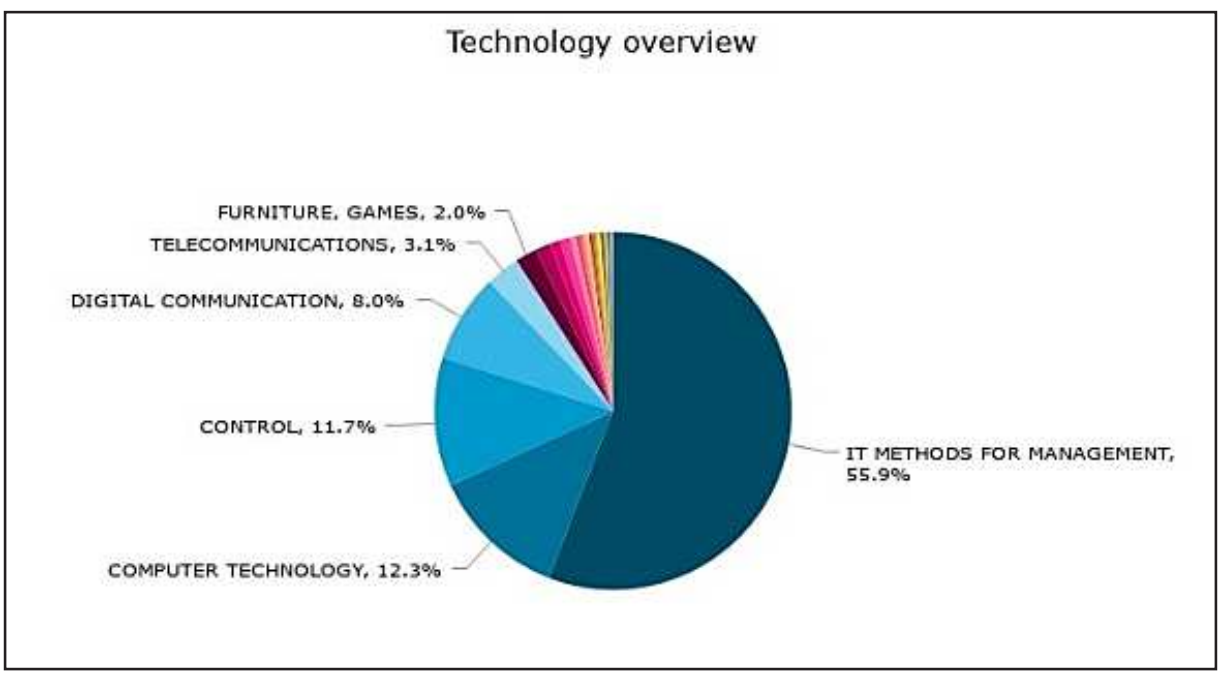

Fonte: Questel-Orbit ${ }^{\circledR}$ (2019)

\subsection{Inteligência Artificial}

Os resultados referentes às empresas depositantes de família de patentes relacionadas à contabilidade e inteligência artificial (Figura 9) apresentam como líder de depósitos a empresa IBM - International Business Machines com 197 famílias de patentes depositadas. Através do programa IBM Research, a empresa norte-americana vem explorando tecnologias e técnicas de inteligência artificial e aprendizado de máquina há décadas. Ela possui um laboratório chamado MIT-IBM Watson, que concentra pesquisas em assistência médica, segurança e finanças para entregá-las às indústrias.

A segunda posição no ranking das principais empresas depositantes de família de patentes relacionadas à contabilidade e inteligência artificial é a empresa Qualcomm, com 147 famílias de patentes depositadas. A empresa norte-americana é líder em tecnologia móvel, e atualmente criou uma solução de inteligência artificial projetada para atender às necessidades de inferência de inteligência artificial em nuvem para provedores de datacenter.

Na terceira posição no ranking das principais empresas depositantes de família de patentes relacionadas à contabilidade e inteligência artificial (Figura 9) está a empresa Microsoft Technology Licensing, com 125 famílias de patentes depositadas. Atualmente, ela trabalha com um produto de inteligência artificial denominado Microsoft Azure, capaz de fazer um computador imitar o comportamento humano inteligente, podendo analisar imagens, compreender a fala, interagir de maneiras naturais e fazer previsões usando dados. 
Figura 9 - Principais depositantes de famílias de patentes relacionadas à contabilidade e inteligência artificial

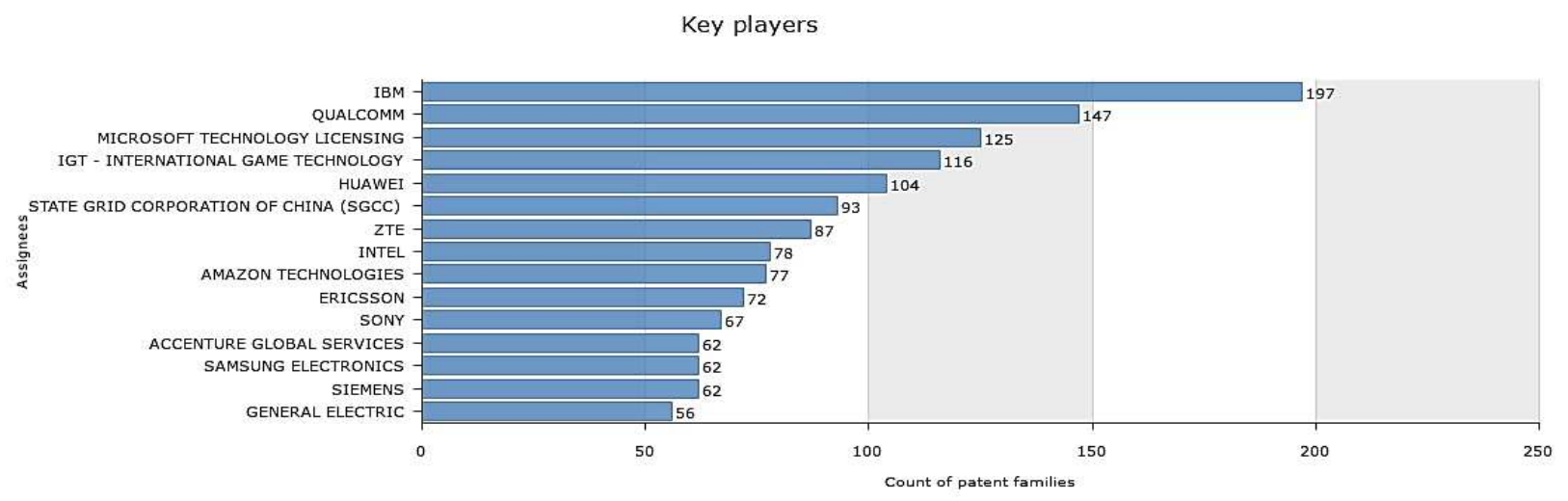

() Questel 2019

Fonte: Questel-Orbit巴 (2019)

Os principais países de proteção das tecnologias voltadas para inteligência artificial são Estados Unidos da América com 4.124 famílias de patentes, seguidos da China com 4.075 famílias de patentes, e do Escritório Europeu de Patentes, na terceira posição com 1.858 famílias de patentes depositadas. O Escritório Europeu de Patentes realiza pesquisas e exames substantivos em um número cada vez maior de pedidos de patentes europeias e pedidos internacionais depositados sob o Tratado de Cooperação de Patentes.

As invenções relacionadas à contabilidade e inteligência artificial possuem uma vasta abrangência de tecnologias. As 12.217 famílias de patentes apresentam predominância de tecnologias referentes a Computer Technology com 20,47\%, It Methods for Management com 20,15\%, Digital Communication com 15,77\%, Control com 9,53\%, Telecommunications com 7,78\%, Measurement com 4,46\%, Audio-visual Technology com 2,40\%, Medical Technology com 2,26\%, Future, Games com 2,11\% e Electrical Machinery, apparatus, Energy com 1,93\% total das famílias de patentes.

\section{Considerações Finais}

Ao concluir a análise de dados, percebe-se que as tendências tecnológicas estudadas estão se desenvolvendo dentro do mercado financeiro como mecanismos que potencializam a mensuração e coleta de dados para serem transformados em dados utilizáveis pelos usuários da contabilidade, agregando qualidade a diversas informações geradas no mercado. De acordo com os resultados resgatados das famílias de patentes relacionando a contabilidade com "data analytics" percebe-se que o mercado é liderado pela empresa Amdocs Development, fornecedora de software e serviços para empresas de comunicação e mídia de todos os portes, com o total de 33 famílias de patentes depositadas. Também é possível perceber grandes players do mercado de tecnologia da informação no rol das principais depositantes, como a chinesa Huawei. Desta forma, a análise de dados torna-se uma diretriz das grandes companhias para melhorar a qualidades das informações para tomada de decisão.

Quanto ao uso de mecanismos envolvendo blockchain, percebe-se que ele é uma tendência tecnológica usada como um novo método para a segurança de informações financeiras tornan- 
do-se uma tecnologia estritamente necessária para salvaguarda e autenticação de informações financeiras dentro de uma "economia virtual", eliminando assim, a necessidade de uma autoridade centralizada para governar e verificar interações e transações entre todos os participantes de uma operação financeira.

Já a Internet das Coisas (IoT/Internet of Things) aponta para uma convergência de múltiplas tecnologias que interagem de forma integrada como a comunicação sem fio por meio de processos automatizados que geram dados de estoques, sistemas embarcados envolvendo a aplicação de raciocínios contábeis e microeletromecânicos. As invenções relacionando a Contabilidade com a Internet of Things possuem uma vasta abrangência de tecnologias: as 995 famílias de patentes apresentam predominância de tecnologias pertencentes à comunicação digital, com $25,12 \%$, métodos de gerenciamento, com $22,86 \%$, controle, com $15,92 \%$, telecomunicações, com $14,14 \%$, tecnologia da computação, com 8,51\%, e mensuração, com 3,23\%. A integração entre a Contabilidade e a Internet das Coisas traz à tona tecnologias que apontam para a automação e registro de operações de forma automatizada e integrada nos processos fabris em linhas de produção e/ou execução de serviços visando a reduzir tempo e custos de produção com informações contábeis sendo geradas e registradas em tempo real.

Ao se observar a disposição dos números de depósitos de famílias de patentes é possível notar a desproporcionalidade entres as inovações tecnológicas, em destaque para a inteligência artificial, que possui um montante de patentes muito superior a todas as outras tecnologias analisadas neste estudo, demonstrando que o seu uso dentro da contabilidade é a maior tendência tecnológica dentro do escopo desta pesquisa. Através do programa IBM Research, a empresa norte-americana vem explorando tecnologias e técnicas de inteligência artificial e aprendizado de máquina há décadas. Ela empresa possui um laboratório chamado MIT-IBM Watson que concentra pesquisas em assistência médica, segurança e finanças para entregá-las às indústrias. O uso de "algoritmos contábeis" tornará a Contabilidade a base conceitual de novas formas de serviços e práticas financeiras que provavelmente serão integradas a todas as outras tecnologias citadas.

Por fim, este trabalho apresenta a possibilidade de diversos estudos específicos e aprofundados sobre as inúmeras aplicações tecnológicas da Contabilidade, bem como estudos mercadológicos sobre o desenvolvimento das inovações oriundas das temáticas: Data analytics, Blockchain, Internet of Things, Auditoria e Tributação e Inteligência Artificial.

\section{Referências}

ABSTARTUPS. Tudo que você precisa saber sobre startups. 2017. Disponível em: https:// abstartups.com.br/o-que-e-uma-startup/. Acesso em: 18 maio 2019.

CARLIN, E. L. B. Auditoria, planejamento e gestão tributária. Curitiba: Juruá, 2008.

CARNEGIE, G.; NAPIER, C. J. "Critical and Interpretive Histories: Insights into Accounting's Present and Future Through its Past". Accounting, Auditing and Accountability Journal, v. 9, n. 3, p. 7-39, 1996.

CONEXÃO FINTECH. O que é Fintech? 2017. Disponível em: http://conexaofintech.com.br/ fintech/o-que-e-fintech/. Acesso em: 7 maio 2018. 
CORDEIRO, J. S.; DUARTE, A. M. P. O profissional Contábil diante da nova realidade. Qualit@s, v. 1, n. 1, 2006.

DUARTE, Roberto Dias. Os impactos da inteligência artificial na contabilidade e no papel do contador 2.0. 2018. Disponível em: https://biracontabilidade.cnt.br/noticias/artigos/2018/01/10/osimpactos-da-inteligencia-artificial-na-contabilidade-e-no-papel-do-contador-2-0.html. Acesso em: 01 fev. 2019.

FINNOVATION. Diferenças entre os bancos e as startups de fintech. 2015. Disponível em: http://finnovation.com.br/diferencas-entre-os-bancos-e-as-startups-defintech/\#sthash.XMOFIMys. dpuf. Acesso em: 6 maio 2018.

FUNDAÇÃO CPqN. Tecnologia Blockchain: uma visão geral. 2017. Disponível em: https://www. cpqd.com.br/wp-content/uploads/2017/03/cpqd-whitepaper-blockchain-impresso.pdf. Acesso em: 8 fev. 2019.

HIEAUX E. Big Data e Internet das coisas serão motores de uma nova economia. jun.2015. Disponivel em: http://computerworld.com.br/big-data-e-internet-das-coisas-serao-motores-deumanova-economia. Acesso: 10 maio 2019.

KAMBATLA, Karthik et al. Trends in big data analytics. Journal of Parallel and Distributed Computing, v. 74, n. 7, p. 2.561-2.573, 2014.

KUPFER, D.; TIGRE, P. B. Modelo SENAI de prospecção: documento metodológico. Capítulo 2: prospecção tecnológica. In: ORGANIZACION INTERNACIONAL DEL TRABAJO CINTERFOR. Papeles de La Oficina Técnica. Montevideo: OIT/CINTERFOR, 2004. n. 14.

OLIVEIRA, André Henrique et al. Aplicações de automação em IOT-Internet of Things. Revista Científica e-Locução, v. 1, n. 10, p. 19-19, 2016.

PURCHIO, Luisa. Como usar a moeda digital Bitcoin. Isto é, 26 fev. 2017. Disponível em: https:// istoe.com.br/349307_COMO+USAR+A+MOEDA+DIGITAL+BITCOIN/. Acesso em: 20 jul. 2018.

PURDY, M.; DAVARZANI, L. The growth game-changer. How the Industrial Internet of Things can drive progress and prosperity. Accenture. 2015. Disponível em: https://www.accenture.com/_ acnmedia/accenture/conversion-assets/dotcom/documents/local/pt-br/pdf/accenture-industrialinternet-things-growth-game-changer.pdf\#zoom=50. Acesso em: 07 out. 2019.

SALAH, K. et al. Blockchain for AI: Review and open research challenges. IEEE Access, v. 7, p. 10.127-10.149, 2019.

SANTOS, Flávia Costa dos. A contabilidade na era digital. Anuário de Produções AcadêmicoCientíficas dos Discentes da Faculdade Araguaia. 2015.

SILVA, Daniel Carmo da. Contabilidade na Era Digital: Um estudo sobre o reconhecimento contábil das transações realizadas com bitcoins no Brasil. Dissertação (Mestrado) - Faculdade de Tecnologia e Ciências Sociais Aplicadas - FATECS. Centro Universitário de Brasília - UniCEUB. 2017.

SILVA, P. O.C.; KRUGER, C. O papel do contador frente às novas tecnologias da escrituração contábil com as empresas. 2012. Disponível em: http://www.eumed.net/cursecon/ecolat/br/13/ contabilidad.html. Acesso em: 14 mar. 2015.

TAURION, C. Big Data. São Paulo: Editora Brasport, 2013. 


\section{Sobre os Autores}

\section{Edilson Ponciano de Lima}

E-mail: edilsonponciano@yahoo.com

Mestre em Propriedade Intelectual e Transferência de Tecnologia para a Inovação (PROFNIT/UFAL).

Endereço profissional: Av. Lourival Melo Mota, S/N - Tabuleiro dos Martins, Maceió, AL. CEP: 57072-900.

\section{Erivaldo Oliveira de Matos}

E-mail: cont.matos@gmail.com

Especialista em Finanças Corporativas, Auditoria e Controladoria (UNIT/AL).

Endereço profissional: Av. Lourival Melo Mota, S/N - Tabuleiro dos Martins, Maceió, AL. CEP: 57072-900.

\section{Vinícius José Ferro Gomes}

E-mail: viniciusferro_8@hotmail.com

Mestre em Propriedade Intelectual e Transferência de tecnologia para a Inovação.

Endereço profissional: Av. Lourival Melo Mota, S/N - Tabuleiro dos Martins, Maceió, AL. CEP: 57072-900.

\section{João Paulo Lima Santos}

E-mail: jpls@lccv.ufal.br

Doutorado em Engenharia Civil pela Universidade Federal do Rio de Janeiro (2011).

Endereço profissional: Universidade Federal de Alagoas, Laboratório de Computação Científica e Visualização,

Cidade Universitária, Maceió, AL. CEP: 57072900.

\section{Danielle Clara Santana da Silva}

E-mail: danielleprpi.ifal@gmail.com

Mestre em Propriedade Intelectual e Transferência de tecnologia para a Inovação.

Endereço profissional: Instituto Federal de Alagoas, Matriz, Rua Doutor Odilon Vasconcelos, n. 103, Jatiúca, Maceió, AL. CEP: 57035-660. 